\title{
Den forlengede arm - materialisering av pisker, hester og ryttere
}

\author{
ANITA MAURSTAD*
}

Title: The extended arm - materializations of horsewhips, horses and riders.

\begin{abstract}
The horsewhip is an interesting object. It works in relationships between animals and humans. In some relationships it can make the horse move forward willingly, with no need for physical contact. In other contexts, the whip can make the horse obey the rider's wishes by gently touching the horse's body. In other kinds of relationships, it paves the way for riders hitting their horses and also feeling regret afterwards.

This article combines insights from two recent research fields - research focusing on materiality and research focusing on the relationship between animals and humans. Research in these fields challenges museum presentations of these topics. The article adopts a performative perspective regarding the whip and its relations and shows how whips, horses and riders are constituted in different practices. Finally, the museum communication of such practices is commented on. The aim is to show how a museological perspective regarding objects and materiality can contribute to the understanding of the importance of seeing objects as relational materialities, as well as to knowledge about the relationship between animals and humans.
\end{abstract}

Key words: Horse, horsewhip, rider, relational materiality, museum, performativity.

INNLEDNING

En av mine daglige gleder er å kommunisere med hest. Jeg har vært rytter de siste tyve år, og eier av hest de siste tre. Ridning krever en del materielt utstyr, og blant mine gjenstander finnes en pisk. Den er slitt. Handtakets prydband holder på å gå i oppløsning. Min pisk er slitt gjennom bruk, men det er en særlig type bruk den har vært delaktig i. Den er i liten grad brukt på de hester jeg har kommunisert med, men jeg har ofte hatt den med på kurs. Det hender instruktørene spør etter den. Mer vanlig er det at den blir liggende på kanten av ridebanen, og etter hvert som jeg har arbeidet med å forstå den bedre, har jeg latt den bli liggende i stallen. Pisken er en kjent gjenstand over store deler av verden. Men det er ikke alle 
steder den brukes slik jeg gjør det. Den er kjent som et disiplinerende instrument. Den har vært, og er også fortsatt noen steder, brukt på barn, på hunder og som avstraffelse der voksne idømmes et antall piskeslag for hendelser som anses uriktige i kulturen. I vestlige kulturer er den ikke like mye brukt lengre. Debatter om oppdragelse, lydighet og korreksjonsmetoder har pågått, og verken hunder, barn eller voksne møter pisken som straff i samme grad som før. For hester er situasjonen annerledes, men også her pågår debatter, som jeg vil vise.

Gjenstanden pisk har, som andre gjenstander, også estetiske kvaliteter. Den har ulik lengde, men ridepisken er vanligvis 50-130 $\mathrm{cm}$, og den kan være vakkert utformet i skinn, med flettete handtak eller andre estetiserende uttrykk. En hestebutikk i dag vil ha et mangfold å velge i, også billigere utgaver i plast, heriblant rosa og lyseblå typer for kundegrupper som verdsetter slike farger. Gjenstandens estetiske kvaliteter er ikke uten betydning. Gjenstandens rosa farge gjør noe med brukeren og hennes relasjon til hesten. Og velger hun lyseblått både har og får relasjonen andre kvaliteter. Gjenstander inngår i relasjoner, der vi gjør både gjenstandene og oss selv.

Det særlige med gjenstanden pisk er at vår bruk av den inngår i en relasjon til en tredjepart, hesten. Bruken gjør noe, både med hesten og vår relasjon til den. Forholdet mellom dyr og menneske er et forsømt tema i kulturhistorien (Thorsen 2006), men har fått mer oppmerksomhet i forskningen de siste to tiårene. Armstrong og Simmons (2007: 1) viser til en 'animal turn' som de mener er sammenlignbar med den lingvistiske vending som revolusjonerte samfunnsvitenskapene $\mathrm{i}$ forrige århundre. Samtidig benytter andre samfunnsforskere begrepet 'material turn' om det ster- kere fokus som er vist materialitet i samme periode. I denne artikkelen kombineres innsikt fra disse to feltene. Jeg vil nytte teoretiske perspektiver på materialitet og vise hvilken rolle gjenstanden pisk kan spille i forholdet mellom dyr og menneske. Mer bestemt vil jeg sette lys på at pisken gjør noe i de relasjoner den inngår i. Den gjør noe med dyrene, åpenbart, men også med menneskene.

Det blikk som anlegges er museologisk. Det har til formål å gjøre museal ekspertise relevant $\mathrm{i}$ dagsaktuelle aktivitets- og forskningsfelt; vår relasjon til ting og vår relasjon til dyr. Museologiske perspektiver bidrar med kunnskap om gjenstanders rolle i utforming av kulturell aktivitet og identitet; hvordan vi bruker gjenstander og gir dem oppgaver som former, vedlikeholder, eller er med på å endre etablerte kulturelle praksiser. Dette er kunnskap jeg vil nytte i min analyse av praksiser der pisker, hester og ryttere inngår. Avslutningsvis reiser jeg noen spørsmål knyttet til museal formidling av de komplekse temafelt som artikkelen problematiserer.

\section{MATERIALITET Og MUSEOLOGI}

Museer er steder hvor materialitet har vært i fokus på ulike måter over lang tid. Mens Ole Worm på 1600-tallet var opptatt av materialers legende kraft og samlet objekter med det som utgangspunkt (Mordhorst 2009), ble man med framveksten av antropologien på slutten av 1800-tallet opptatt av ting som kulturhistoriske representanter (Conn 2009). Etter hvert, rundt 1960-tallet, fulgte kunnskapspolitiske spørsmål ved objekters representativitet: Hvem har valgt å vise akkurat dette? Hva sier det om den kultur som beskrives? Er det representativt og etisk riktig overfor det folk det snakkes om (Dubin 2006, Fyfe 2006, 
54 Macdonald 1998)? Dagens spørsmål er i større grad kunnskapsteoretiske, knyttet til hva materialitet og materiell kultur er. Pearce (2010) framholder at ettersom vi er materielle vesener som engasjerer oss i materielle omgivelser, produserer vi både individuelle og sosiale vaner på dette grunnlag. De materielle elementenes betydning for hvem vi er, er oversett, mener hun, og tar til orde for en større vektlegging av hva ting betyr i utformingen av kultur. Miller (2005) er også opptatt av at materialitet og menneskelighet er tett forbundet. Han refererer til at vi vokser opp i sosiale grupper med klare forventninger til hvordan hverdagslivets ting skal brukes og hva som er relasjonene mellom dem. Tingene vi omgir oss med bestemmer hvordan vi orienterer oss $\mathrm{i}$ verden. Våre holdninger til materielle ting utgjør selve drivkraften i hvordan vi deltar og hvordan vi vil at verden skal være. Men som Pearce poengterer han at materialitetens virkning ofte er usynlig. Tingene inngår i rammer for handlinger som, når de virker, er usynlige. De inngår i sosiale praksiser som er så tatt for gitte at vi ikke ser dem. Og vi reflekterer sjelden over de materielle elementene i våre kommunikasjoner og handlinger $\mathrm{i}$ verden. De er bare naturlige, og trivielle.

Min hest oppfatter absolutt ikke pisken som triviell. Han reagerer sterkt på den. Jeg trenger bare ha den under armen, som man holder en avis, for at nytten oppnås: Hesten går villig og ivrig fram, altfor ivrig egentlig. Han synes ikke å tenke annet enn på at fram skal vi. Dette gjør inntrykk på meg. Gjenstanden pisk virker på min hest ved sitt blotte nærvær. For andre hester trenger det ikke være slik. Hester og ryttere som har daglig omgang med pisken kan ha et annet forhold til den, gjøre den til noe annet, gi den en annen utsagnskraft. I det følgende vil jeg analysere uli- ke møter mellom mennesker, pisk og hest og vise noen av piskens identiteter. Denne type praksisstudie følger av det teoretiske fokus det er eksempler på hvordan den materielle gjenstanden pisk inngår i handlinger og kultur som kan si noe om hva den er. Mitt praksisfokus følger også av et nettverksteoretisk blikk på materialitet, slik redegjort for av Law (1999). Han lanserer begrepet 'relasjonell materialitet' for å understreke at det er en rekke elementer, både menneskelige og ikke-menneskelige, som inngår $\mathrm{i}$ et fenomen (Law 1999: 3). Det er relasjonene mellom elementene som avgjør fenomenet, og relasjonene må iscenesettes. Damsholt og Simonsen (2009: 25) har oversatt begrepet iscenesettelse til 'gjøren' på dansk, et begrep som også kan benyttes på norsk. Begrepet gjøren åpner for å se hvordan mennesker og ting sammenveves i aktiviteter med ulike effekter. En effekt er virkningen på hva ting er. Ting materialiseres. De blir til i prosesser, og de kan med andre ord komme i mange versjoner avhengig av hvilke sammenvevinger de inngår i (Mol 1999). En annen effekt er virkningene på oss. Damsholt og Simonsen (2009) mener at også vi gjøres i vår gjøren, og Frykman og Gilje (2003) fremmer perspektiver på hvordan identitet formes både av handlinger så vel som av mentale refleksive konstruksjonsprosjekter. Dette gir grunnlag for spørsmål om hvordan bruken av pisk har betydning også for hvem vi er. Kommer også vi i flere versjoner avhengig av hvordan vi bruker denne materielle gjenstanden?

Perspektiver på relasjonell materialitet gir interessante koblinger mellom materialitetsteori og museologi (Maurstad 2012). Ettersom ting gjøres i relasjoner, med virkninger som er så tatt for gitte at de ofte er usynlige, er museal framstilling av gjenstander en utfordring. Tingene gjør noe, er relasjonelle materialiteter 
også på museum, men det å vise de mange mulige versjonene er problematisk, ettersom museene er steder der gjenstandene vanligvis "låses" i en fortelling. Den følgende analyse av pisken som relasjonell materialitet vil ikke bare vise at gjenstander kan ha komplekse identiteter. Jeg vil også drøfte museets rolle i det å framvise materialitetens kompleksitet og relasjonelle væren. Med det illustrerer artikkelen hvordan materialiseringsperspektiver er viktige, både for studier av samfunnsfenomen som forholdet mellom hest og rytter, og for tenkning rundt den museale behandling av gjenstander.

Materialet som ligger til grunn for analysen er dels flere års egne erfaringer og observasjoner av andres bruk av pisk i hesteholdet. Jeg har søkt å forstå gjenstandens betydning gjennom flere år. Jeg har spurt og sett på mer kunnskapsrike ryttere enn meg selv og fătt forskjellige svar. Jeg støtter meg også til lærebøker om ridning og hestehold, samt blogger om bruk av pisk. Jeg vil starte med å vise til hva en rekke eksperter, dvs. ryttere som har skrevet bøker om hestehåndtering, sier om bruk av pisk. Dernest vil jeg analysere noen blogger som tematiserer pisk. Bloggene nytter jeg fordi de er beskrivende for hverdagshåndteringen av denne gjenstanden. På bloggene framtrer en rekke stemmer som sier hva de mener om pisk og hest. Stemmene er inspirerte, de kommenterer noe andre har sagt eller ment, og i sine kommentarer gir de ofte også beretninger om hva de selv gjør. De er med andre ord gode kilder til piskens hverdagslige identiteter. De er ikke nødvendigvis representative for bestanden av ryttere, men det er ikke viktig i denne sammenheng. Det som er viktig er at de forteller noe om bruk som er vesentlig. En rekke mennesker bruker pisken på en annen måte enn ekspertene anviser. Blogger- nes detaljerte bekjennelser gjør det mulig å forstå pisken som en gjenstand som får identitet gjennom bruk og som også gjør noe med brukeren.

\section{HESTEHÅNDTERING}

En av de første skriftlige kilder om hestehåndtering er Xenophons arbeid. Xenophon var gresk historiker, soldat og filosof og levde mellom 430 og 354 år f.Kr. Han hadde som mål å gi råd til den som skaffer seg hest, skriver han i forste kapittel i boka The Art of Horsemanship, og han tematiserer både anskaffelse, stell og håndtering $\mathrm{av}$ hesten (Xenophon 2006). Xenophons instrukser er interessante. Hva angår kjøp må man se til at man ikke blir lurt, for eksempel på hestens alder. Han snakker selvsagt til en samtid, og selv om vi også i dag assosierer begrepet hestehandel til noe lureri, er det langt fra den situasjon som Xenophon beskriver, der lureri ser ut til å ha vært vanlig, til i dag hvor avtaler om kjøp av hest ofte er kontraktsfestede, og hester har stamtavler og id-merking. Hva angår stell gir han instrukser om hvordan børste hestene. Målet er ikke bare ren hest, men kontakt med hesten. Den skal ha det godt. Utstyr og ridning behandles også, og som ved børstingen er det den milde håndteringen som står i sentrum.

Om pisken skriver Xenophon lite, men han nevner den i en særlig situasjon. Den kan brukes for å stimulere en vegrende hest til å hoppe over ei grøft. Det er ikke rytteren som bruker pisken, men en som står bak. Den vegrende hesten får et piskeslag og vil alltid senere hoppe over grøfter. Ellers virker det som om Xenophon ikke pisker hesten. Tvert imot: I ridningen skal en søke å arbeide med hesten på en måte som får fram en hest som gleder seg over å gå i god rund form, sier han. En skal 
søke å få fram de bevegelser den selv nytter når den springer mot flokken, mot hopper for eksempel. Ved at hesten får ros for å forflytte seg i en form som er dens egen, vil den ta glede over å bli ridd. Det er slike hester en ønsker. En hest som bare gjør ting under tvang er en uglad hest og ingen god hest.

Vicki Hearne, som skriver om kommunikasjon med dyr og bruker sin egen kommunikasjon som trener av hest og hund som referanseramme, refererer til disse perspektivene til Xenophon (Hearne [1986] 2007). Hun bringer fram et eksempel fra egen trening av hesten Drummer Girl, en hest som kom til henne fordi fire andre trenere hadde gitt den opp. Hesten var rasende. Den sparket etter Hearne straks den kom ut av hestehengeren. Hearne brukte de første dagene til å få i gang kommunikasjon med hesten og fikk snart til å ri den. Hennes treningsprinsipp var å sette hesten i posisjoner der den hadde valg, og stimulere den til å velge det riktige, dvs. det treneren ønsket den skulle gjøre. De første dagene nektet den å la seg fange. Hearne jaget den rundt i hesteinnhegningen ei tid for så å stoppe og tilby den grimen. Hesten brydde seg lite om tilbudet. Hearne jaget den videre, kom med nye tilbud og etter ei tid syntes Drummer Girl at grimen var å foretrekke framfor å springe rundt og rundt. Den stakk hodet inn i grimen og var fanget.

Samme prinsipper anvendte Hearne i ridningen. Det å hoppe over hinder viste seg å være en særlig utfordring. Hesten likte å hoppe, men den hadde utviklet seg til å bli en som bare sprang på straks den så et hinder. Hearne tenkte ikke på å disiplinere den slik at den var rolig før den skulle hoppe. Den skulle få gjøre dette som den hadde så lyst til. Men den skulle stoppe, etter hinderet. Hearne lot den gå fram i full fart mot hinderet. Etterpå ba hun først pent om stopp. Det virket ikke. Da ba hun på en mer brutal måte. Hun rykket i den ene tøylen slik at hestens hode vrengtes bakover. Hun visste at den kunne stoppe. Derfor skulle den stoppe når den fikk beskjed.

Når jeg trekker fram dette eksemplet er det for å illustrere flere ting. Hearne bruker ikke pisk. Men hun bruker smerte. Hun har stor respekt for hesten, og hennes bruk av smerte er knyttet til at hun vil ha dens respekt. Det inngår i hennes kommunikasjon. Dyr må være lydige, vis a vis hverandre, og vis a vis mennesker, på samme måte som også mennesker er lydige. I daglig adferd følger vi en rekke kjente regler. Trening av dyr handler om å etablere kjente regler for rett og galt. Men dyr er ikke mennesker, og ulike dyr må respekteres for at de er andre vesener enn oss, med andre språk. Mennesker må lære seg hvordan kommunisere på betingelser som kan oppfattes og forstås. Hearne mener Drummer Girl lærte av episoden. Hun begynte å gå slik Xenophon beskrev - i god form foran hinderet. Hun måtte lære seg å takle at hun skulle stoppe brått etter hinderet. Det kunne hun kun gjøre når hun brukte sin egen kropp på måter hun selv kjente var lure for å møte denne utfordringen.

Andre hesteeksperter, som Monty Roberts, tar sterk avstand fra bruk av straff, i betydningen smerte, $\mathrm{i}$ sin hestetrening. Roberts vokste opp i etterkrigstidas USA på en gård der hestetemming var en daglig aktivitet. $\mathrm{Og}$ smerte var en del av hestetemmingen. Hesten skulle utmattes i prosesser der målet var å bryte ned dens viljestyrke og evne til å gjøre motstand (Roberts [1996] 2008: 25). Hesten ble bundet opp mens treneren hev sekker mot kroppen dens for å skremme og utmatte den. Dens ene ben ble bundet opp til en løkke rundt halsen. Sal ble også lagt på mens benet var bundet. Roberts beskriver disse trenings- 
metodene som å innebære mye smerte, frykt og også skader for hestene. Han kontrasterer sine egne med sin fars treningsmetoder. Roberts kommuniserer med hester på måter som viser hestene at han forstår dem. Ved hjelp av kroppsspråk gir han beskjeder til hestene, er lydhør for respons, og belønner når hesten handler riktig. Og Roberts' metoder virker. Mens hans far trengte flere uker på å temme hester, klarer Roberts jobben på timer.

Roberts er i dag berømt for sine metoder. Han korrigerer hester, men uten smerte. Som Xenophon og Hearne er han opptatt av at hester som trenes riktig har glede av å løpe. Roberts har også gått sterkt ut som motstander av pisk: "Til dags dato er det min fulle overbevisning at pisker skulle vært forbudt. Hvis vi utnytter hestenes genuine ønske om å løpe når vi trener dem, trenger vi ingen pisk. Jeg vil ikke se en pisk i nærheten av mine staller - sånn er det med den saken" (Roberts [1996] 2008: 50).

En annen hestetrener, Louise Nathorst, er mer moderat. Hun skriver at pisken kan være nødvendig under trening og utdanning (Nathorst 2002). Den er uunnværlig under unghestutdanning, da den klargjør betydningen av den drivende sjenkelen for hesten. Sjenkelen er rytterens fot, og en drivende sjenkel er en fot som klemmer lett mot hestekroppen og med det gir signaler til hesten om å gå fram. Pisken kan legges ved sjenkelen for å klargjøre eller forsterke budskapet. Men den skal ikke benyttes til avstraffelse, det understreker hun, og viser i den forbindelse til et gammelt ordspråk: "Der kunsten stopper, begynner volden" (Nathorst op.cit. 47). I de konkurranser hun deltar i, dressurridning, er pisk forbudt, så Nathorst veksler mellom å ri med og uten pisk under trening. Målet er å få hesten følsom og lydig for de øvrige hjelperne, sete og sjenkel, sier hun.
Med referanse til de nevnte hestefolkene er det allerede klart at pisken kommer i ulike versjoner. Den er en hverdagsgjenstand for noen. Den brukes aktivt i veddeløp, så aktivt at Roberts finner det nødvendig å motarbeide den. Han opponerer ikke bare i nevnte sitat fra første bok, men også i senere bøker (Roberts 2005) der han argumenterer for at den må ut av veddeløpssporten. Og Roberts er ikke hvem som helst. Han har en verdensberømmelse å lene seg til. Hvorvidt det er hans arbeid som har gitt resultater er vanskelig å si, men bruken av pisk i veddeløpssporten er under debatt. Mange land har forbudt den, men ikke alle. I august 2009 introduserte styret i den australske veddeløpsorganisasjonen nye regler for hvor mange ganger hesten kan slås i innspurten i galoppløpene. ${ }^{1}$ Jockeyene raste, og de streiket. De argumenterte med at dette var ufornuftig - det sto om deres sikkerhet. Forhandlingene mellom styret og jockeyforbundet forte til en enighet september samme år om tillatte 7 piskeslag de siste 100 meterne før mål. Pisken skulle ha en særlig type polstring som skulle gjøre den mindre smertefull. ${ }^{2}$ Jockeyene fikk beholde pisken som hverdagsgjenstand, men bruken ble noe regulert.

Pisken er også en hverdagsgjenstand for Nathorst. Hun bruker den i trening av sine hester. Men den er neppe så hverdagslig at den er usynlig for henne. Hun har et refleksivt forhold til når hun skal bruke den. Nathorst er klassisk dressurrytter, og i denne sporten kalles pisken ofte "den forlengede arm". Ideene bak uttrykket er basert på teorier om hesten, teorier som iscenesetter noen særlige versjoner av hest, rytter og pisk. Teoriene sier blant annet at hester reagerer på trykk. Dette utnytter mennesker og har konstruert et språk med signaler som hesten læres. I klassisk ridning er det slik at sjenkelen trykker på begge sider av 
58 hesten for å få den til å gå fram, og hvis det trykkes på en side, viker den unna sjenkelen. Sjenkeltrykket kan som nevnt forsterkes ved pisk som legges til mot hestekroppen ved sjenkelen. En kan også legge pisken ved skulderen for å få hesten til å flytte skulderen sin. Straks den ønskete adferd oppnås tar man vekk trykket. Brukt på denne måten blir pisken en forlengelse av armen, fordi man kan legge press på flere steder på hesten enn det menneskets arm eller fot klarer alene.

En må spørre om trykk med pisken virker motiverende fordi hesten har kjent dens smerte, at de engang har "smakt pisken"? Ikke nødvendigvis. Man kan, som hestetrener Ellen Ofstad praktiserer, lære hesten å flytte seg for pisken gjennom det hun kaller "positiv forsterkning". "Å trene med positiv forsterkning," sier Ofstad, "handler ikke om å gi hesten mat, men om å gi den noe den liker og få den til å assosiere dette med en bestemt adferd og dermed bli motivert til å gjenta denne. Alt mulig kan fungere som en positiv forsterker som for eksempel å få gjøre en favorittøvelse, eller å bli klødd på manken eller for den sakens skyld mat."3 Hesten kan altså flytte seg for pisken fordi den har assosiert pisken med mange doser havre eller annet hestegodt. Pisken trenger slik sett ikke involvere smerte. Slik som beskrevet ovenfor, basert på teorier om hestehold, kan pisken inngå i en kommunikasjon som ikke involverer smerte, men bidra til å gi klare beskjeder fra en leder, en trener, en som hesten må adlyde, og som den vil adlyde.

Denne gjennomgangen av ulike eksperters forhold til pisk, er ikke ment å være en uttømmende beskrivelse av feltet hestehåndtering. Jeg har vist til noen utvalgte eksperter for å vise at forholdet mellom eksperter og erfaringer er komplekst. Ekspertene snakker ut fra erfaringer med hester. De har ulike meninger.
Det finnes eksperter på feltet som sier at en må være varsom med pisken. Den skal ikke slå. Det jeg også har søkt å vise er at disse ekspertene definerer pisken $\mathrm{i}$ ord og handling som en myk gjenstand, en del av kroppen, en forlenget arm. Den formuleres ikke som like myk av alle. Roberts nekter å bruke den. Det er interessant $\mathrm{i}$ denne sammenheng å vise til at han selv har smakt den. Roberts har fătt mye juling av sin far, sier han. Han har egne erfaringer med den smerten som pisken kan utøve i relasjoner. Som ekspert på pisk har han med andre ord flere erfaringsfelt å trekke på.

Endelig er formålet med denne korte presentasjonen av ekspertuttalelser først og fremst å se den som bakgrunn for det som følger - en gjennomgang av praksiser. Som jeg vil vise er praksiser steder hvor materialiteten får en egen agens, en agens annerledes enn som en myk arm. Pisken får snakke selv, utover ordene til ekspertene.

\section{BLOGgERNES PISK}

Live Bonnevie, forfatter og blogger på temaet hest, har en blogg om pisk. ${ }^{4}$ Hun starter med å stille spørsmål ved hvorfor det er uakseptabelt å slå en hund, mens det er akseptabelt å slå en hest. Hun viser videre til observasjoner av situasjoner der hester blir slått. En situasjon er dressurshesten som etter hvert blir latere, dvs. som ikke "byr like mye fram" som før. Bonnevie bruker et kjent rytterspråk i sin forklaring av situasjonen. Man bruker pisk for å "vekke hesten" i stedet for å "mase med sjenklene". Rytteren bruker pisken for å minne den latere hesten om at kravene omkring lydighet for sjenkel fortsatt er gyldig. En hest som lytter mindre og mindre til sjenklene kalles 'sjenkeldød', og pisken skal forhindre at dette skjer. 
En annen situasjon som Bonnevie observerer er en hest som blir slått gjentatte ganger uten at hun kan se hvorfor. Hun spør og făr til svar at hesten kan ingenting.

Den tredje situasjon hun refererer til i bloggen er en jente som skal hoppe hinder for første gang. Hun er usikker. Det er også hesten, og den stopper foran hinderet. Jenta får beskjed av ridelæreren om å "gi han en smekk" og prøve igjen. Hun får også vite at hun kan ødelegge hesten dersom hun aksepterer at han stopper. Det er det samme som om at "hun lar den vinne".

Bonnevie er kritisk til bruken av pisk i alle disse situasjonene. Hun mener det er greit å bruke pisken som en forlenget arm, som en "tegngiver", men ikke som et instrument som avgir slag som korreksjon. Hun mener også at mange av situasjonene der pisken anvendes slik skyldes manglende kompetanse hos rytteren og hun spør "hvorfor vi ukritisk utstyrer småjenter med ridepisk før de i det hele tatt har lært å ri?"”

Hun får mye respons på bloggen. Skrevet ut i A-4 format utgjør svarene og kommentarene hele 12 sider. En jente tar opp spørsmålet om bruk av pisk når sjenklene ikke lengre virker like godt. ${ }^{5}$ Hun sier at det er bedre å bruke pisk enn å sitte og sparke hesten. Denne forståelsen er interessant. Jeg ser den som et uttrykk for at det kan reflekteres over bruk av pisk uten at all dens synlighet likevel demonstreres. Refleksjoner kan komme til å inngå i tatt for gitte mønstre som låser mulighetsområdet for tenkning rundt hva slags gjenstand pisken er. Refleksjonene skjer innenfor en begrenset ramme der hverdagsligheten til gjenstandene avgrenser hvilke versjoner en kan se og reflektere over. Denne jentas refleksjoner forteller at pisken er en selvsagt gjenstand i dialogen mellom hest og rytter, eller rettere: det pisken gjør med hesten er så selvsagt - korreksjon i form av straff er selvsagt. Hvilken straff blir da et spørsmål om valg mellom to onder. Når jenta ikke har pisk må hun sparke. Hun er derfor også selv materialisert som en som yter straff og blir innenfor denne konteksten. Hun klarer ikke reflektere seg ut av den. Den teoretiske forlengete arm, der pisken er et instrument som legges til, og virker, er langt ute av syne. Skulle den hatt plass i akkurat denne forbindelsen mellom jente, hest og pisk, hadde hun måttet gjøre noe for å finne ut mer om hvorfor hesten har sluttet å høre på henne.

Mange av bloggerne uttrykker at det er på rideskolene de lærer å bruke pisk. Ridelærere instruerer dem og insisterer på piskebruk, hevdes det. De fleste har selv gått på rideskoler og brukt pisken. Mange uttrykker anger; de er motstandere av piskebruk nå. En person sier det slik: "Jeg har utrolig mye jeg ønsker å ta tilbake. Og jeg tror det er i tankene mine hver dag når jeg er i stallen. Kan gi hesten min en ekstra kos og et rosende ord pga angeren." En annen, en voksen dame, uttrykker tristhet over møtet med en 6-åring som kommer fra rideskolen og har lært hva hun skal gjøre når hesten ikke vil gå. Hun er trist over at de fortsatt lærer å bruke pisken slik på rideskolen.

De angrende rytterne er interessante. Pisker, hester og ryttere har over tid inngått i noen relasjoner som har materialisert særlige versjoner av alle tre. Pisken er et instrument å slå med, hesten opplever smerte, og rytteren, ja hva med henne? Rytteren har hatt mer eller mindre suksess med å få sin vilje med hesten gjennomført. Rytterne har brukt pisken som et hverdagsinstrument i en særlig forstand; de har slått uten å reflektere. Men så tar de pisken ut av hverdagsfæren og gjør den til gjenstand for refleksjon, og da skjer noe nytt: De nye tankene materialiserer mennesker med sorg. 
Noen har interessante forklaringer til hvorfor eller hvordan de kom til å slutte med piskebruk. En jente opplevde å bli slått "på det kalde låret" av en venninne. Det skjedde som en spøk, men det gjorde vondt. Hun skriver: "Etter dette har jeg tenkt meg nøye om hver gang jeg tenker på å bruke en pisk." Som i eksemplene med de angrende rytterne er det refleksjoner som gir henne adgang til nye versjoner av pisken. Men det er også noen særlige opplevelser som avstedkommer refleksjonene.

Hva angår det å selv smake pisken - et kjent utsagn som definerer en klar identitet til pisken - vitner også andre innlegg på bloggen om piskens smertelige identitet. En jente bruker pisk, påfører ingen skade sier hun, blir endatil sint når noen slår hunder. Men hun bruker altså pisk i sin ridning, og slår seg selv: ”jeg smekker bare til støvelen min med pisken", sier hun. Dette er det flere som uttrykker. Pisken brukes til å slå sine egne støvler med. Hesten kjenner jo lyden og vet at nå smaker den pisken - i alle fall er det like før. Disse menneskene som slår seg selv, er også materialisert som noen som slår. De har ikke forlengede armer. De kan bekjenne seg til teorien kanskje, men det er ikke den som gjøres i praksis.

Så langt Live Bonnevies blogg. I andre blogger finner jeg eksempler på at folk mener det er greit å bruke pisken. På forum.dyrenett.no ${ }^{6}$ skriver en person at så lenge hesten har fătt flere muligheter til å velge å gjøre det den blir bedt om, er han eller hun "ikke redd for å gi hesten et lite klask av pisken". En annen forteller om hvordan personen bruker pisken som insektsvifte - for å rekke fram til kleggen som sitter på rumpa til hesten, eller på hodet. Denne personen bruker også pisken når hesten mister konsentrasjonen. Da får den "en smekk" og dette er "vanligvis nok til fange oppmerksomheten hennes resten av økten".
Videre brukes pisken når hesten blir treg i trav og når rytteren har for lite bein i sideførende øvelser.

Noen viser til farlige situasjoner og forsvarer å bruke pisk der. Det gis eksempler som at hesten går langs en trafikkert veg og må holde seg på vegkanten. Pisken hjelper til å holde den der. Til dette finnes det også svar av en annen blogger som mener man må lære seg å kommunisere med hesten før man går langs vegen.

Også denne bloggen har sine motstandere av det å bruke pisk. En person skriver om hvordan han eller hun brukte pisken en dag, reflekterte over situasjonen og kom til at det var urettferdig da han eller hun "virkelig tenkte etter”. Refleksjonene omkring det å slå får betydning for personens identitet. Dette kommer fram i det personen sier om situasjonen i dag: "Jeg savner ikke pisken i det hele tatt, og hver gang jeg havner i en situasjon hvor jeg og hesten kommer i konflikt er jeg lykkelig når jeg kan velge en annen metode (som kanskje tar litt lenger tid) på å løse situasjonen, enn å bruke pisken som tvang og voldsmiddel... jeg er stolt hver gang jeg løser en situasjon uten bruk av pisk!!!"

Den tredje bloggen jeg vil vise til er hestemarked.no. ${ }^{7}$ Her finner vi en som sier at dressurspisken er et supert hjelpemiddel: "Pisken er super når man vil lære hesten bakdels- og fordelsvendinger, sideførende øvelser og hos meg galoppfatninger." Pisken legges på rompa, presses inntil, sier personen. Videre kan pisken brukes når "hestens tanker vandrer bort i drømmeverden". Et klaps med pisken på egen støvel lager en lyd som vekker hesten. Innskriveren sier at dette ikke er en erstatning for den varierte trenings betydning for å holde hestens oppmerksomhet, men det kan likevel "være kjekt å bruke" i noen situasjoner. 
Her finnes det også råd om type pisk. En jente anbefaler en type som lager mye lyd og som ikke svir i lang tid etter at den er brukt. Hun begrunner dette logisk: "Det sier seg jo selv at om man bruker en vanlig ridepisk (som svir) og hesten gjør ting riktig, hvordan skal man da få riktig timing på hjelpere og ettergift, hvis det fremdeles svir der pisken ble brukt?"

\section{FENOMENET PISK}

Pisken er en interessant materiell gjenstand; i utseende en tynn pinne med elastisitet og med funksjonsområder godt kjent i de fleste kulturer. Den assosieres med disiplinering og $\mathrm{i}$ mange tilfeller også med smerte. Jeg har imidlertid her identifisert noen personer som rytterkulturens eksperter, og mange av ekspertene innskriver gjenstanden som noe som ikke involverer straff eller vold. Den er en del av rytterens kropp i kommunikasjon med hesten, en forlengelse av armen. Disse ekspertene gjør et arbeid med de kjente kulturelle definisjonene av pisk, et arbeid som er både teoretisk og praktisk, det skjer i snakk og i handling. Pisken sies å utvide rytterens mulighet til å nå punkter på hestekroppen som en vil være i dialog med. Et lett press, ikke et piskeslag, vil flytte hestens skulder eller ben. Dette arbeidet er ambisiøst. Kjente versjoner av pisken skal avlæres. Det kulturelt potente, for ikke å si kompetente, disiplinerende instrumentet blir noe som inkorporeres i menneskets kropp. Gjennom denne måten å snakke om pisken, søkes dens smertelige funksjoner fjernet.

Den er imidlertid fortsatt disiplinerende, også som inkorporert i kropp. Hele rytteren er et disiplinerende element. Relasjonen rytter hest er en situasjon der rytteren utøver tvang, også uten pisk. Sjenkler, sete/vekt og hender, kalles de tre primære hjelperne på ryttersprå- ket, og de brukes alle i den hensikt å få hesten terens ønske at den skal gjøre. Patton (2003) viser til både Roberts' og Hearnes' ulike filosofier og kommenterer begrepet tvang nærmere. Tvang er essens i trening. Men det finnes ulike typer tvangsmidler. Patton understreker at dressurs og hopp er aktiviteter hestene deltar i fordi de er trent til det, og de er trent for å tilfredsstille trenernes kulturelt tilegnete ønsker. Han spør om enhver trening av dyr da er en kooptering av dyr og deres egne verdier og svarer negativt med referanse til at trening er en relasjon mellom dyr og menneske som er naturlig. Lydighet er noe som er gyldig i alle relasjoner, også mellommenneskelige. Lydighet mellom dyr og menneske har en tosidighet i seg. Dyret lærer å utføre noen oppgaver, men det inkluderer også hvordan te seg vis a vis mennesker. Og det er en gjensidighet i dette. Treneren har også et ansvar for å se og forstå at dyret er noe i seg selv. Den gode trener er den som ser og forstår disse forskjellene og har stor oppmerksomhet på hva hun sier og gjør.

Pisken kan fungere disiplinerende, men uten smerte, under disse betingelser. Brukt som tegngiver, på måter der oppgavene som hesten skal utføre innlæres med positiv forsterkning, er det ingen smerte å oppleve, verken for hest eller rytter. Det ser imidlertid ut til at denne bruk er en vanskelig praksis. Arbeidet med å gjøre den kulturelt kjente gjenstanden pisk til noe kroppslig inkorporert i form av en forlenget arm virker for ambisiøst. I mange rytteres hender blir pisken et instrument for å påføre hesten smerte. Det virker som om den teoretiske definisjonen av pisken som den forlengede arm kan legitimere dens plass i relasjonen mellom hest og rytter, i første omgang. Men så skjer det noe i praksisene som gjør at pisken trer ut av denne versjonen 
62 og inn i en annen. En blogger beskriver dette som følger: "Pisken er jo egentlig et hjelpemiddel, en forlengelse av hånden din. Men den ble brått endret til et straffemiddel.” Bloggeren beskriver overgangen som brå. Og det er selvsagt en overgang fra den ene materialitet til den andre som er faktisk på et gitt tidspunkt, og som slik sett er brå. Men jeg tror det er viktig å se forståelsen som ligger bak endringen i praksisene rundt piskebruk, og som ligger bak denne endringen i piskens identitet, som mer glidende - som prosessuell, relasjonell og avhengig av praksiser. Pisken er for uerfarne ryttere ukjent som en forlenget arm. Den er kjent som et disiplinerende instrument i den kultur rytterne er vokst opp i før de ble ryttere. Dette er dens mest hverdagslige kvaliteter. Skal den ha reell funksjon som en forlenget arm må dette læres. Og det må gjøres. Den uerfarne rytter må lære å gjøre dette disiplinerende instrumentet til en del av sin egen kropp, og nytte det uten voldelige eller smertelige hensikter. Den forlengede arm må gjøres hverdagslig i praksiser. Dette er et stort arbeid, og det ser ut til at det bare er kunnskapsrike ryttere som får dette til. Det krever mye kunnskap om ridning, om hest, om relasjoner hest, pisk og rytter, å bruke den slik.

Men interessant er det også at erfaring med bruk av pisk gir noen personer som angrer. De reflekterer over smerten, det å bruke pisk som smerteinstrument: "Etter å ha tenkt nøye", som noen sier, over "alle de gangene jeg faktisk ubevisst har misbrukt pisken", ser de pisken i en smerteversjon og angrer. Og mange avstår da fra å bruke den. Eller de tar en del av smerten selv. De slår sine støvler, og hesten får kun deler av smerteopplevelsen. Den făr lyden, trusselen om straff.

Pisken kommer med andre ord i mange versjoner, og til hver versjon av pisk finnes det en menneskelig versjon. Bruken av pisk, og refleksjonene rundt det, skaper mennesker. Det skaper identiteter (Frykman og Gilje 2003). Det å trene hest er bygging av identitet gjennom praksiser med hest - og det betyr noe hva en gjør - det betyr ikke bare noe for hesten, og for kommunikasjonen mellom menneske og hest. Det betyr også noe for en selv, for hvem man er.

Oppsummeringsvis vil jeg vektlegge at på tross av at jeg har vist at pisken kommer $\mathrm{i}$ mange versjoner, er noen versjoner mer dominerende enn andre. Det kulturelle instrument som skremmer hesten er betydningsfullt. Som jeg beskrev innledningsvis har min hest rett pisken har stor utsagnskraft ved sitt blotte nærvær. Den kan fort gjøre meg til en som slår, og hesten min til en som blir slått. Det er kanskje dette som ikke er nok tatt på alvor en manglende refleksjon over gjenstandens iboende kulturelle utsagnskraft. Uten slik refleksjon materialiserer vi lett pisken som det vi vet den er - noe å slå med.

\section{MUSEENE OG PISKEN - NYE RELASJONSHISTORIER?}

Min analyse av praksiser der pisk inngår har satt lys på to ting; gjenstanden som relasjonell materialitet og hva den kan gjøre i relasjonen mellom dyr og menneske. Og pisken kan gjøre mer. Den kan gjøre en jobb på museet. Museer er først og fremst kjent for sine store gjenstandssamlinger. Som jeg skisserte innledningsvis har etterspurte kvaliteter ved samlete gjenstander variert over tid. Med bred pensel viste jeg til at materialets legende kraft på et historisk tidspunkt var viktigere enn selve formen på gjenstanden eller dens identitet som for eksempel leirkrukke (Mordhorst 2009: 11). På et senere tidspunkt kom dens kultur- 


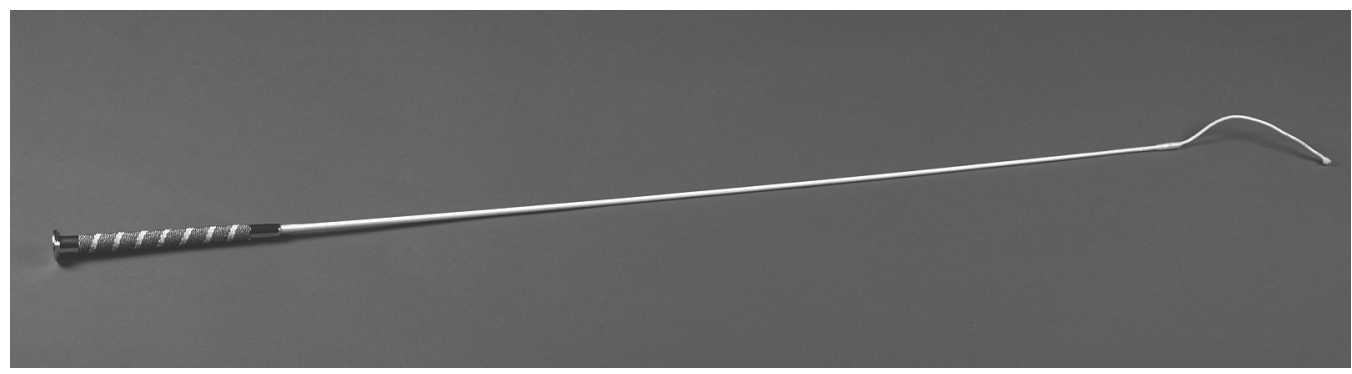

Fig. 1. Ridepisk. 2013. Foto: June Asheim, Tromsø Museum - Universitetsmuseet.

historiske representasjonsverdi i sentrum, etter hvert også dens kunnskapspolitiske verdi. I dag er det flere som stiller kunnskapsteoretiske spørsmål til museets samlinger og formidling rundt disse, både med hensyn på hva ting betyr i sosialt og kulturelt liv og mer bestemt hva det betyr at museer viser noen særlige ting. Hvordan museer gjør det er også et sentralt tema, noe den kritiske museologien har som oppgave å problematisere (Bugge Amundsen og Brenna 2010: 18). Knell (2004: 15) mener også at museer trenger en dypere forståelse for materiell kultur og hva denne kan gjøre på museum. Museer må være mindre opptatt av nostalgi, og mer spørre hva og hvordan en potensiell museumsgjenstand vil bidra til vår evne til å vite, mener han. Dette er interessant i lys av det Eriksen (2009: 123) reiser som problemstilling i sin kulturhistoriske analyse av norske museer. Hun spør om museer kan arbeide med en mer nyskapende tilnærming til identitetsproblematikk knyttet til begrep som demokrati, kommunikasjon og bidrag til sameksistens? Eriksen viser til at framveksten av folkemuseene ved utgangen av 1800-tallet ga en museumskompetanse, en måte å forstå museer på, som er paradigmatisk og som ser museer som minnesteder. Museer arbeider med identitet, men det er en historiserende identitet. Tenkningen bygger på at vi må kjen- ne hvor vi kommer fra for å forstå hvem vi er, og museer samler i stor grad gjenstander som sier noe om hvor vi kommer fra.

Eriksen viser til at det ser ut til å være vanskelig å forene museers samlingsarbeid med en identitetsrefleksjon som ikke er historisk fundert. Jeg vil tro at pisken kan gjøre en jobb her. En nytenkning rundt gjenstander, som jeg har invitert til her, kan være en måte å arbeide med nåtidig funderte identitetsrefleksjoner, ikke bare om hvordan være borgere vis a vis hverandre, men knyttet til det tema jeg har fokusert her; vårt forhold til dyr. Jeg vil også tro at de to tingene kan henge sammen. Som forskere i feltet har fokusert, er relasjonen mellom menneske og dyr identitetsfremmen$\mathrm{de}$ - vi blir til i vår omgang med dyr (Haraway 2003, Irvine 2004).

Det vil by på en rekke utfordringer for museene å ta inn de performative perspektiver som jeg har skissert som viktige identitetsgivende kapasiteter. Ideen om tings representasjonsverdi står sterkt i museal bevissthet. Den relasjonelle verdi som jeg har vektlagt vil møte motstand. En utstilt pisk vil for eksempel lett snakke til publikums museumskompetanse og deres kulturelle kompetanse. Pisken er et disiplinerende instrument i folks bevissthet generelt, og på museum spesielt. Den oppfattes lett som utstilt for noen særlige egenskaper - en- 
ten har den tilhørt en historisk person, eller den har en særlig funksjon. Og i begge tilfeller er dens disiplinerende kvaliteter tydelige. Gjenstanden trenger hjelp dersom hele spekteret av dens relasjonelle sider skal avdekkes.

Museer kan yte slik hjelp. I produksjonen av utstillingen Australian Journeys, er Wehner og Sear (2010) opptatt av å bruke gjenstander for å formidle livsverdener og stedsproduksjon som former australsk liv og knytter Australia til andre steder i verden. De vil at tingene skal fortelle, få vise sin egen utsagnskraft, men også formidle at denne kan være mangfoldig. Et grep som velges er å stille ut gjenstander i montre på måter som gjør at gjenstandene forteller flere historier avhengig av hvilken side i monteren man ser inn i. Dette å vise at objektet kan forstås ulikt og fra mange ståsteder er også et grep som kan formidle piskens mange versjoner. Ett scenario er rideskolejenta, et annet er den voksne erfarne Nathorst. Det særlige design for framstillingen av de to brukerne av pisk, enten den er i montre eller ved andre hjelpemidler, må utvikles nærmere. Poenget er at museet kan fortelle relasjonshistorier ved hjelp av objekter. Og med det kan museet bidra på nye måter, ikke bare med å snakke om gjenstanders relasjonelle karakter, men også i det å trekke dyrene inn i kulturhistorien. Så langt er dyrene på museum i stor grad naturfagenes domene. Og de sosiale og kulturelle kvaliteter som dyrene måtte ha, er det naturforskere som uttaler seg om (Birke 2009). I lys av det økende antall grupper som tar til orde for dyrs rettigheter, på måter som Hearne ([1986] 2007) beskriver som farlige, med henvisning til at et syn på hunders rettigheter til et godt liv har gitt løse hunder i parker, uten oppdragelse og lydighet, er det nødvendig å tematisere dyr i kulturhistorien, særlig den framtidige. Deres og vår lydighet vis a vis hverandre, er tema som er viktige samfunnsspørsmål. Hearne brukte smerte i sin trening. Mange gjør det, mange er uenige, og museet kan bidra i debattene om vårt forhold til dyr blant annet ved å sette piskebruk på hest inn i en kulturfaglig ramme; barn har fătt ris, noen får det enda; hunder det samme; hva med hesten? Er den et vesen som må disiplineres med pisk, også i dag? Hvordan kan vi i så fall bruke pisken uten å materialisere oss selv som noen som slår? Eller sagt med noen andre ord: hvordan kan vi bruke den på måter som inngår i en identitetsproblematikk knyttet til begrep som kommunikasjon og bidrag til sameksistens, som Eriksen (2009) er opptatt av?

Og endelig - hvordan kan vi bruke pisken på museet til å vise at museal ekspertise er relevant i dagsaktuelle aktivitets- og forskningsfelt? For pisken kan bidra til vår evne til å vite på flere måter. Den kan gi oss en utvidet forståelse av materialitetens relasjonelle karakter, relasjonen mellom dyr og mennesker, og museenes bidrag som kunnskapsleverandører på disse feltene.

\section{NOTER}

1. http://www.brisbanetimes.com.au/sport/horseracing/horse-whipping-most-people-dont-give-astuff-20090911-fkaq.html Lastet ned 17.10.11

2. http://www.australianracingboard.com.au/Media.whip-rules Lastet ned 17.10.11

3. http://www.ellenofstad.com/Artikler/artikler.htm Innlegg under overskrift Spørsmål og svar: "Hva mener du om Monty Roberts metoder?" Lastet ned 2.11.11

4. http://www.hest.no/blogg/?bid=34497\&blid $=675705$ Lastet ned 17.10.11

5. Noen av bloggerne opptrer med navn. I disse tilfeller refererer jeg til dem som hun eller han. An- 
dre har identiteter som er kjønnsnøytrale. Her anvender jeg kjønnsnøytrale begreper som 'person', eller 'blogger'.

6. http://forum.dyrenett.no/forum/showthread. php?66823-Bruk-av-pisk! Lastet ned 17.10.11

7. http://mix.hestemarked.no/pop_printer_ friendly.asp?TOPIC_ID=1376 Lastet ned 17.10 .11

\section{LITTERATUR}

Armstrong, Philip og Simmons, Laurence: "Bestiary: An Introduction". I Laurence Sommons og Philip Armstrong (red) Knowing Animals. Brill: Leiden, Boston 2007: 1-27.

Birke, Lynda: "Interwoven Lives: Understanding Human/Animal Connections". I Tora Holmberg (red) Investigating Human/Animal Relations in Science, Culture and Work. Centrum för genusvetenskap: Uppsala Universitet 2009: 18-33.

Bugge Amundsen, Arne og Brenna, Brita: "Museer, kritisk museologi og tverrfaglige museumsstudier”. I Bjarne Rogan og Arne Bugge Amundsen (red) Samling og museum. Kapitler av museenes historie, praksis og ideologi. Novus Forlag: Oslo 2010: 9-23.

Conn, Steven: Do Museums Still Need Objects? University of Pennsylvania Press: Philadelphia 2009.

Damsholt, Tine og Gert Simonsen, Dorthe: "Materialiseringer. Processer, relationer og performativitet". I Tine Damsholt, Dorthe Gert Simonsen og Camilla Mordhorst (red) Materialiseringer. Nye perspektiver på materialitet og kulturanalyse. Aarhus Universitetsforlag: Århus 2009: 9-39.

Dubin, Steven C.: "Incivilities in Civil(-ized) Places: 'Culture Wars' in Comparative Perspective". I Sharon Macdonald (red) A Companion to $\mathrm{Mu}$ seum Studies. Blackwell Publishing: Malden, Oxford, Victoria 2006: 477-94.

Dudley, Sandra H.: "Museum Materialities: Objects, Sense and Feeling". I Sandra Dudley (red) $\mathrm{Mu}$ - seum Materalities. Objects, Engagements, Interpre-

tations. Routledge: London and New York 2010: 1-19.

Eriksen, Anne: Museum. En kulturhistorie. Pax Forlag A/S: Oslo 2009.

Frykman, Jonas og Gilje, Nils (red): Being There.

New Perspectives on Phenomenology and the Analysis of Culture. Nordic Academic Press: Lund 2003.

Fyfe, Gordon: "Sociology and the Social Aspects of Museums". I Sharon Macdonald (red) A Companion to Museum Studies. Blackwell Publishing: Malden, Oxford, Victoria 2006: 33-50.

Haraway, Donna: A Companion Species Manifesto:

Dogs, People, and Significant Other-ness. Prickly Paradigm: Chicago 2003.

Hearne, Vicki: Adam's Task: Calling Animals by Name. Skyhorse Publishing: New York [1986] 2007.

Irvine, Leslie: If You Tame Me. Understanding Our Connection with Animals. Temple University Press: Philadelphia 2004.

Knell, Simon J.: "Altered Values: Searching for a New Collecting". I Simon Knell (red) Museums and the Future of Collecting. Ashgate: Aldershot 2004: 1-47.

Law, John: "After ANT: Complexity, Naming and Topology". I John Law og John Hassard (red) Actor Network Theory and After. Blackwell Publishers/The Sociological Review: Oxford 1999: 115.

Macdonald, Sharon: The Politics of Display: Museums, Science, Culture. Routledge: Oxon, New York 1998.

Maurstad, Anita: "Cod, Curtains, Planes and Experts - Relational Materialities in the Museum". Journal of Material Culture Vol. 17, nr 2, 2012: 173-189.

Miller, Daniel (red): Materiality. Duke University Press: Durham and London 2005.

Mol, Annemarie: "Ontological Politics. A Word and 
Some Questions”. I John Law og John Hassard (red) Actor Network Theory and After. Blackwell Publishers/The Sociological Review: Oxford 1999: 74-90.

Mordhorst, Camilla: Genstandsfortallinger. Fra Museum Wormianum til de moderne museer. Museum Tusculanums Forlag: København 2009.

Nathorst, Louise: Dressursridning. Landbruksforlaget: Oslo 2002.

Patton, Paul: "Language, Power, and the Training of Horses". I Cary Wolfe (red) Zoontologies. The Question of the Animal. University of Minnesota Press: Minneapolis 2003: 83-101.

Pearce, Susan: "Foreword". I Sandra H. Dudley (red) Museum Materalities. Objects, Engagements, Interpretations. Routledge: London and New York 2010: xiv-xix.

Roberts, Monty: Mannen som lytter til hester. Oversatt av Morten Haugen. Pocketforlaget: Oslo [1996] 2008.

Roberts, Monty: Fra mine hender til dine. Landbruksforlaget: Oslo 2005.

Thorsen, Liv Emma: "Kampen om territoriet - $\AA$ skrive dyrene inn i kulturhistorien". Tidsskrift for kulturforskning. Vol 5, nr. 1, 2006: 23-38.

Wehner, Kirsten og Sear, Martha: "Engaging the Material World: Object Knowledge and Australian Journeys". I Sandra Dudley (red) Museum Materalities. Objects, Engagements, Interpretations. Routledge: London and New York 2010: 143-162.

Xenophon: The Art of Horsemanship. Oversatt til engelsk av Morris H. Morgan. Dover Publications, Inc.: New York 2006.

\author{
*Anita Maurstad, PhD, er professor $i$ \\ kulturvitenskap ved Tromsø Museum - \\ Universitetsmuseet.
}

Adresse: Tromsø Museum - Universitetsmuseet, Universitetet $i$ Tromsø, NO-9037 Tromsø, Norge

E-mail: anita.maurstad@uit.no 